\title{
CPA Firms' Hiring Preferences AND THE 150-Hour REQUIREMENT
}

\author{
A. Bruce Caster, Wanda Causseaux, and Courtney Droms
}

A. Bruce Caster is Associate Professor of Accounting, Utica College. Wanda Causseaux is Assistant Professor of Accounting, Siena College. Courtney Droms, Assistant Professor of Marketing, Butler University.

\section{ABSTRACT}

The 150-hour rule for CPA licensing has been widely adopted throughout the US and its territories. However, the CPA licensing requirements in most jurisdictions allow multiple options for fulfilling that requirement. (NASBA, 2013b) Specifically, candidates can satisfy the 150 -hour requirement by completing an undergraduate degree followed by a graduate degree, or they can take all 150 hours at the undergraduate level. Additionally, students can choose to seek a position with a CPA firm immediately after completing their undergraduate degrees and then finishing the 150 hours while working, or they can choose to finish all 150 hours before trying to enter the job market. To date there has been no evidence presented which would indicate the degree to which CPA firms prefer any of these approaches. The purpose of this research was to provide that evidence. 
42 The BRC Academy Journal of Education Vol. 4, No. 1

Keywords: Accounting education, CPA firm hiring, 150-hour requirement

DOI: http://dx.doi.org/10.15239/j.brcacadje.2014.04.01.ja03

\section{INTRODUCTION}

There are 55 jurisdictions (states and territories) in the U.S. which grant CPA licenses under the auspices of the AICPA using the Uniform CPA Exam (NASBA, 2013b). Each jurisdiction has the authority and the responsibility to determine its own requirements for CPA licensure. In general, those requirements revolve around three factors:

Education. A candidate must complete a prescribed program of study to become eligible for CPA licensure.

Examination. A candidate must take and pass the CPA Exam (and perhaps also another exam, if required by that specific jurisdiction) to become eligible for $\mathrm{CPA}$ licensure.

Experience. A candidate must complete a period of experience in accounting practice become eligible for CPA licensure.

The 150-hour rule, the subject of this research, requires that a candidate complete at least 150 semester hours of higher education to be eligible for CPA licensure. To date, 48 jurisdictions have implemented some form of 150-hour rule, and three more will implement one by 2015 . On its face, the 150-hour rule is an educational requirement because it defines the amount of education a candidate must complete to be eligible for CPA licensure. However, in 31 of the 51 jurisdictions which have adopted, or will soon adopt, the 150-rule, it is also an examination requirement. Those 31 jurisdictions require candidates to complete all 150 hours before they are eligible to sit for the CPA Exam.

The CPA licensing requirements in most jurisdictions allow candidates multiple options for fulfilling the 150 -hour requirement. Specifically, candidates can choose to complete an undergraduate degree 
followed by a graduate degree, or they can choose to complete an undergraduate degree and then take an additional 30 hours of undergraduate courses. Similarly, candidates can choose to seek a position with a CPA firm immediately after completing their undergraduate degrees and then to finish the additional 30 hours while working. Or they can choose to complete all 150 hours before trying to enter the job market.

There are compelling arguments for and against each of these options. For example, earning a graduate degree conveys a certain prestige. However, not all students are going to be eligible for admission to a graduate program, and tuition for graduate courses is often higher tuition for undergraduate courses. On the other hand, taking the additional 30 hours of undergraduate courses might allow a student to complete a second degree in an accounting-related field like finance or computer science. But in schools which have graduate programs, higher-level accounting courses are frequently offered only at the graduate level and might not be available to students not admitted to a master program.

Similarly, getting a job immediately after completing the undergraduate degree can be a financial necessity for many students, and since many states require several years of work experience before a candidate is eligible for CPA licensure, there is no rush to finish the additional 30 hours. However, many students discover that the work load in a CPA firm makes it extremely hard to take additional courses, even on a parttime basis. In addition to work, travel requirements, particularly for auditors, can interfere significantly with regular class attendance. Those are compelling reasons for finishing all 150 hours before entering the job market.

The survey was conducted in Georgia, but there is no reason to expect that this result is unique to that state. The State of Georgia implemented the 150-hour rule 15 years ago, and by now Georgia CPA firms have had a lot of experience with CPA-ready and non-CPA-ready candidates (NASBA, 2013a). Observers in Georgia thought they had been noticing this preference for CPA-ready candidates developing over time. Little 
change was noted during the first few years after the 150-hour rule was adopted, but starting about 10 years after the rule was adopted, more and more position announcements started to appear which contained language like, "CPA-ready candidates preferred." The same degree of preference for CPA-ready candidates might not yet be observed today in states like New York, which only implemented the 150-hour rule 5 years ago. But there are good reasons why that preference might develop over time: The work load and travel schedules for many staff accountants make regular class attendance very difficult. Furthermore, employers might not want to be responsible for balancing work/school conflicts on behalf of employees who are still trying to complete the 150-hour requirement.

The question that really needs to be answered is whether CPA firms have any preferences regarding the strategies which students adopt for finishing the 150-hour requirement. These are strategic choices which accounting students have to make as they design their academic programs of study, but there is not currently any empirical evidence available to guide them in these choices. The purpose of this research is to provide that evidence.

\section{Research Approach}

A survey was developed to examine the research questions in this study, and it was sent to CPA firms in the State of Georgia. The first section of the survey asked respondents to characterize their firm's hiring policies with respect to CPA-ready candidates. They were given a 7-point Likert scale, with 7 being, "We only hire CPA-ready candidates," and 1 being, "No hiring preference." A follow-up question asked how much additional salary (how much of a "salary premium") their firm might offer to a CPA-ready candidate, as compared to the salary they might offer to a candidate who was not CPA-ready. Salary brackets were provided, and the subject was asked to indicate the amount of the salary premium by 
selecting the appropriate bracket. Subjects whose answers to the first question indicated that their firms would only hire CPA-ready candidates were asked to skip this question. If any of those subjects did answer this question their answers were disregarded.

In the second section, subjects were provided with 4 different hiring scenarios which asked them to choose between two hypothetical job candidates. In each scenario, both candidates were described as having completed Georgia's 150-hour requirement, but they had done so using different strategies. The subject was first asked to indicate the preferred candidate using a 1 - 7 Likert scale, where 1 was "strongly prefer" one of the candidates, 4 was "no preference" between the two candidates, and 7 was "strongly prefer" the other candidate. A follow-up question asked how much more the firm would be willing to offer to preferred candidate as opposed to the other candidate (Dennis, 2000). Salary brackets were provided, and the subject was asked to select the appropriate bracket.

The third section explored subjects' expectations regarding the contents of a typical undergraduate accounting degree. They were asked to imagine that they were interviewing a candidate who had earned an undergraduate accounting degree but had not taken any additional course work beyond the requirements for that degree. Subjects were then presented with a list of course titles for 14 common Accounting and Business Law classes, and they were asked to indicate how likely it was that this candidate had taken each of these courses. They were given three levels of likelihood to choose from for each course:

- Definitely was defined as, "you believe this course is normally a required course in an undergraduate accounting program, so this candidate definitely would have taken this course."

- Possibly was defined as, "you believe that this course is normally offered as an elective in an undergraduate accounting program, so this candidate may or may not have taken this course." 
- Unlikely was defined as, "you believe that this course is not usually offered in an undergraduate accounting program, so this candidate probably did not take this course."

Finally, section four of the questionnaire asked for information about the firm, including size (both in terms of employees and in terms of total revenues) and scope (local, regional, national, or international). The purpose of this information was to allow the researchers to judge whether or not the sample group was representative and the extent to which the research results might be generalized to the larger population of CPA firms.

\section{Sample Selection and Survey Process}

The sample selection process began with a list of all firms that were members of the Georgia Society of CPAs. Firms were excluded from the data sample if they were extremely small (fewer than three professional staff members), if they stated that their practice was restricted to services for which the 150-hour requirement was irrelevant (e.g., consulting or tax preparation), or if they did not have an office within the State of Georgia. The final sample group contained 338 Georgia CPA firms. Questionnaires were mailed to all firms in the sample group during the first week of October, 2010, and follow-up questionnaires were sent to non-responding subjects four weeks later. A total of 98 responses were received, which represented a $28 \%$ response rate.

\section{Results for Section 1: Preference for CPA-ready Candidates}

The results for the first section of the survey showed an extremely strong preference for CPA-ready candidates. As shown in Figure 1, only $9 \%$ of the subjects indicated that they were indifferent regarding whether or not a candidate was CPA-ready. By contrast, $60 \%$ expressed a strong 
preference $(4,5$, or 6$)$ for CPA-ready candidates, and $13 \%$ indicated that they would only hire CPA-ready candidates.

The follow-up question, addressed only to subjects who indicated that their firms are willing to hire candidates who are not CPA-ready, was, "How much more would your firm be willing to pay for a CPA-ready candidate?" As shown in Figure 2, 76\% said they were willing to offer a salary premium of more than $\$ 1,000$ to get a CPA-ready candidate, and $15 \%$ said they were willing to offer more than $\$ 5,000$.

\section{Results for Section 2: Hiring Preferences by Educational BACKGROUND}

The second section of the questionnaire provided the subjects with 4 different hiring scenarios which asked them to choose between two hypothetical job candidates. In each scenario, both candidates were described as having completed Georgia's 150-hour requirement, but they had done so using different strategies. Each scenario was accompanied by a pair of questions, the first of which asked which candidate the subject preferred and how strong that preference was, and the second of which asked how much more the firm would be willing to pay to hire the preferred candidate.

\section{Results for Hiring Scenario 1}

Scenario 1 asked the subject to choose between the following two candidates:

- Candidate J had completed an undergraduate accounting degree and then had taken 30 additional hours of undergraduate courses to fulfill the 150-hour requirement.

- Candidate K had completed an undergraduate accounting degree and then had earned a Master of Accountancy degree.

As shown in Figure 3, 62\% of the subjects showed some degree of preference for Candidate $\mathrm{K}$, the candidate with a masters degree, and $46 \%$ 
showed a very high degree of preference (responses 6 or 7). However, $33 \%$ of the subjects indicated that they were indifferent between the two candidates and $4 \%$ preferred Candidate J.

As shown in Figure 4, most subjects also indicated that they were willing to pay more for their preferred candidate. Almost half were willing to pay an additional $\$ 1,000$ to $\$ 5,000$, and nearly one-fourth were willing to pay more than $\$ 5,000$. Since virtually none of the subjects selected Candidate $\mathrm{J}$ as their preferred candidate, that result is equivalent to saying that firms were willing to pay that additional amount of salary to hire a candidate with a masters degree in accounting.

\section{Results for Hiring Scenario 2}

Hiring scenario 2 asked the subject to choose between the following two candidates:

- Candidate L had completed an undergraduate accounting degree and 30 additional hours of undergraduate courses to fulfill the 150hour requirement.

- Candidate $M$ had completed an undergraduate accounting degree and had earned a specialized masters degree in Accounting (e.g., MTax).

The results, shown in Figure 5, indicated that $77 \%$ of the subjects preferred Candidate $M$, the candidate with a masters degree in a specialized area of accounting. Only $18 \%$ were indifferent between $L$ and $M$, and only $3 \%$ preferred L.

As shown in Figure 6, subjects were willing once again to offer a higher salary to their preferred candidate, with $83 \%$ indicating they would offer a salary premium in excess of $\$ 5,000$ and $9 \%$ indicating they would offer more than $\$ 10,000$. Since virtually no subjects preferred Candidate $L$, that is the equivalent to saying that firms were willing to pay that additional amount of salary to hire a candidate with masters degree in a specialized area of accounting 


\section{Results for Hiring Scenario 3}

Hiring scenario 3 asked the subject to choose between the following two candidates:

- Candidate $\mathrm{N}$ had completed an undergraduate accounting degree and 30 additional hours of undergraduate courses to fulfill the 150hour requirement.

- Candidate $\mathrm{O}$ had completed an undergraduate accounting degree, including the necessary courses to earn a Certificate in Internal Auditing, and 30 additional hours of undergraduate courses to fulfill the 150 -hour requirement.

As shown in Figure 7, the subjects were substantially indifferent between these two candidates: $53 \%$ indicated no preference. The remaining $47 \%$ was split almost evenly between the two candidates, with 28\% preferring Candidate $\mathrm{M}$ and $19 \%$ preferring Candidate $\mathrm{M}$.

Somewhat surprisingly, given how few subjects expressed any high degree of preference for either candidate, Figure 8 shows that some of the subjects were still willing to offer a significant salary premium for their preferred candidate, whichever candidate that was. Thirteen percent were willing to offer a premium in excess of $\$ 5,000$, and $2 \%$ were willing to offer more than $\$ 10,000$.

\section{Results for Hiring Scenario 4}

Finally, hiring scenario 4 asked the subject to choose between the following two candidates:

- Candidate P had completed an undergraduate accounting degree and had earned a Master of Accountancy degree.

- Candidate $Q$ had completed an undergraduate accounting degree and had earned a specialized masters degree in Accounting (e.g., MTax).

The results in Figure 9 show substantial indifference (32\%) between the two candidates, though there might be a slight preference for Candidate 
P. It appeared that the choice between these candidates was perceived as being less clear-cut than, say, the choice between a candidate with a masters degree and a candidate without one. That impression was reinforced by one subject who crossed out the Likert scale on the questionnaire and added a note in the margin which said, "It would all depend on what type of position I'm recruiting for."

The impression that this choice was not clear was further reinforced by the salary premium results in Figure 10 . Only $20 \%$ of the subjects would offer their preferred candidate, whichever one that was, a salary premium of more than $\$ 5,000$, and only $5 \%$ would offer more than $\$ 10,000$.

\section{Correlation between Strength of Preference and Amount of Salary Premium}

A follow-up test was performed on the results for this section of the survey, a test of the degree of correlation between the strength of the subjects' preference for a particular candidate and the amount of the salary premium which that subject would be willing to offer to that candidate. The results showed clearly that not only are CPA firms willing to pay for what they want, but the more strongly they want it, the more they are willing to pay it. Table 1 reports that the correlations are all positive and all significant beyond the .005 level.

\section{Results for Section 3: Courses Included in an Undergraduate Accounting Degree}

Section three addressed subjects' perceptions of the contents of an undergraduate Accounting degree. The results, presented in Table 2, show two important results. First, most of the ratings are substantially in agreement with the curricula at most of the Georgia colleges and universities which currently offer Accounting degrees. Most of those schools require Intermediate Accounting, Cost, Individual Income Tax, 
and External Audit, and many also require Accounting Information Systems. In any school where one of these courses is not required, that course is usually offered as an elective. On the other hand, Business Law (UCC) is not as common a requirement as it was 15 or 20 years ago. Only two results are really at odds with normal curriculum requirements: First, although 83\% expected that Corporate Income Tax would normally be required for all undergraduate accounting students, that course is seldom required though it is usually available as an elective. Second, almost half the subjects expected that Taxation of Partnerships, Estates, and Trusts would be required of all undergraduate accounting students. In fact, that course is usually taught only at the graduate level and is rarely available even as an elective in an undergraduate program. With those two exceptions, however, the results indicate that the perceptions of CPA firm recruiters regarding which courses baccalaureate graduates have taken are substantially in line with reality.

The other, and perhaps more interesting result relates to a question which was not explicitly asked in the survey: How many hours of accounting and business law do you think undergraduate accounting student take? By summing the number of courses which each subject coded as "Definitely" taken, one can make some inferences regarding the subjects' perceptions of the total number of hours required in a typical undergraduate accounting program. Figure 11 shows that $64 \%$ of the subjects believed students have to take least 27 hours of required upperdivision courses in accounting and business law, $48 \%$ believed they have to take 30 hours or more, and $12 \%$ believed they have to take 36 or more hours. Furthermore, most subjects indicated that, in addition to the courses they coded as "Definitely" (required), there were additional courses which they coded as "Possibly" (probably offered as electives). The implication is that these subjects believed that the program of study for the accounting degree contains at least three hours of accounting electives in addition to the required hours shown in 


\section{The BRC Academy Journal of Education Vol. 4, No. 1}

In fact, the undergraduate programs of study at most Georgia schools do not exceed 21 to 24 semester hours of accounting and business law courses. And including the electives there are rarely more than 30 hours of accounting and business law in an undergraduate accounting degree. Thus it is fair to say that close to half of all the subjects overestimated the contents of an undergraduate accounting degree by at least $10 \%$, and fully a quarter of them overestimated it by at least $20 \%$.

\section{Summary ANd Conclusion}

The primary focus of this research was to guide strategic choices which accounting students have to make in designing a 150-hour program of study: Should the student complete the 150 hours before entering the work force, or should the student get a job immediately after completing the undergraduate degree and then finish the other 30 hours over time? And should all 150 hours be taken at the undergraduate level, or should the last 30 be done through completing a masters degree? The results show clear answers to both those questions.

When it comes to the question of whether or not to finish the 150 hours before entering the work force, the results were quite clear. The subjects showed a strong and consistent preference for CPA-ready candidates, that is, candidates who have already completed the 150-hour requirement. In fact, $13 \%$ of the subjects indicated that their firms only hire CPAready candidates, and many of subjects whose firms are willing to hire candidates what are not CPA-ready indicated that their firms would be willing to pay a higher salary to hire candidates who were CPA-ready.

Regarding the second question, whether or not to pursue a masters degree, the results were a little less clear. When given a choice between a candidate with an accounting masters degree with no area of specialization (e.g., a Master of Accountancy) or a candidate without a masters degree, one-third of the subjects said they were indifferent between the two. However, virtually of those who did express a preference said 
they would prefer the candidate with the masters degree. By contrast, when the choice was between a candidate with an specialized accounting masters degree (e.g., a Master of Taxation) or a candidate without a masters degree, far fewer subjects were indifferent between the two candidates, and far more of the subjects expressed relatively strong preferences for the candidate with the masters degree. However, when asked to choose between two candidates with masters degrees, more than half the subjects were indifferent. And those who did have a preference were split just about evenly between the two candidates.

Thus, this survey suggests three important lessons, both for faculty and administrators who are designing accounting programs and also for accounting students who are designing their own programs of study.

1. Students need to finish the 150 hours before they try to go to work in a CPA firm, and accounting programs need to be designed to encourage students to do so. CPA firms show a strong hiring preference in favor of candidates who are "CPA-ready," and many firms will not even consider candidates who are not CPA-ready.

2. The 150-hour program of study needs to include a masters degree. CPA firms show a significant preference for candidates who have completed a masters degree as opposed to candidates who completed the 150 hours entirely at the undergraduate level.

3. Look for specializations that might be available in graduate programs which might make those programs distinctive. While the subjects in this study preferred candidates with masters degrees, they were even more enthusiastic about a candidate with a masters degree in a specialized area in accounting than they were about a candidate with a more generic accounting masters degree.

There were also several unanticipated results from this survey. They were not part of the original research design, but they seem worthy of comment nonetheless. One of those results was the $28 \%$ response rate from this survey. That is a relatively high response rate for survey research (Baruch, Yehuda and Brooks C. Holtom, 2008), and the authors consider it to be especially high since the survey was conducted during 


\section{The BRC Academy Journal of Education Vol. 4, No. 1}

the fourth quarter of the year, which not a particularly slack time in public accounting firms. Not only did a substantial proportion of the subjects respond to the questionnaire, many of them also took the time to complete all (or virtually all) of the questions, and a significant number added comments in the margins. It was clear that these busy professionals considered this survey to be important, and they took it very seriously. At the very least, that can be interpreted as evidence supporting the validity of these results.

The other unanticipated result was the extent to which many of these practicing CPAs seemed to overestimate the contents of an undergraduate accounting degree. Fully half of them seemed to think the 120 -hour undergraduate contains at least $10 \%$ more hours in accounting and business law than it probably does, and at least a quarter overestimated its content by $20 \%$ or more. This result suggests that many accounting practitioners may not fully appreciate the value that is added by the additional 30 hours required by the 150 -hour rule.

\section{Limitations AND UNANSWERED QUESTIONS}

This study is subject to many of the limitations common to survey research. Chief among these is the risk that the subjects who chose to respond might not be representative of the larger population. The survey did attempt to gather information about characteristics of the responding firms, and that information indicated that the sample included broad cross-section of the population: small local firms, major regional firms, and even the local office of at least one of the Big 4 firms. Still, the possibility that these results are not representative of the larger population of CPA firms in other states cannot be disregarded.

Another limitation was that the survey was sent to CPA firms in just one state, Georgia. That state adopted the 150 -hour rule 15 years ago, and that fact might make the results non-comparable with the results of other states. Specifically, it is possible that CPA firm preferences about issues 
like CPA-ready candidates might evolve over time, so the preferences displayed by firms in other states, particularly states which have only recently adopted the 150-hour rule, may be different.

There are also many questions this research left unanswered. For example, the survey only included four "hiring scenarios," so it only provided a very limited set of insights into hiring preferences. That was done deliberately in an effort to keep the questionnaire short enough that filling it out would not be seen as burdensome. That choice may have contributed to the high response rate, but it also seriously limited the questions which could be addressed. Still, there are other questions worth exploring.

As suggested above, it would be helpful to have more information about different types of degrees which might be attractive to CPA firms. This study only examined two graduate accounting degrees, a relatively generic Master of Accountancy and a more specialized degree like a Master of Taxation. The current results showed that candidates with masters degree are preferred to candidates without one, and they also suggested that a more specialized masters degree might be somewhat preferred over a more generic one. But this study was not able to offer much guidance regarding which of the multitude of available masters degree specializations are currently more in demand. Further work which provides answers to some of those questions would be very important.

\section{REFERENCES}

Baruch, Yehuda and Brooks C. Holtom (2008), "Survey Response Rate Levels and Trends in Organizational Research," Human Relations, 61 (8), 1139-1160. http://dx.doi.org/10.1177/0018726708094863

Dennis, A. (2000). No One Stands Still In Public Accounting. fournal of Accountancy, fune, 67-74. 
56 The BRC Academy Journal of Education Vol. 4, No. 1

NASBA. (2013a). NASBA Licensing: Georgia. Retrieved from http:// www.nasba.org/licensure/nasbalicensing/georgia-2/

NASBA. (2013b). NASBA Boards of Accountancy. Retrieved from http:// www.nasba.org/stateboards/

\section{Web Appendix}

A web appendix for this paper is available at:

http://dx.doi.org/10.15239/j.brcacadje.2014.04.01.wa03

\section{Citation Information}

Caster Bruce A., Wanda Causseaux, and Courtney Droms. "CPA Firms' Hiring Preferences and the 150-Hour Requirement." The BRC Academy fournal of Business 4, no. 1 (2014): 41-56. http://dx.doi.org/10.15239/ j.brcacadje.2014.04.01.ja03 